Research article

Open Access

\title{
Nipple aspiration and ductal lavage in women with a germline BRCA1 or BRCA2 mutation
}

\author{
Gillian Mitchell ${ }^{1}$, Yoland C Antill2, William Murray ${ }^{1}$, Judy Kirk ${ }^{3}$, Elizabeth Salisbury4, \\ Geoffrey J Lindeman ${ }^{5}$, Juliana Di lulio ${ }^{6}$, Alvin D Milner ${ }^{6}$, Lisa Devereaux ${ }^{7}$ and Kelly-Anne Phillips ${ }^{1}$
}

\author{
1Division of Haematology and Medical Oncology, Peter MacCallum Cancer Centre, Melbourne, Australia \\ ${ }^{2}$ Research Division, Peter MacCallum Cancer Centre, Melbourne, Australia \\ ${ }^{3}$ Familial Cancer Service, Westmead Hospital, Sydney, Australia \\ 4Department of Pathology, Westmead Hospital, Sydney, Australia \\ ${ }^{5}$ Family Cancer Centre, Royal Melbourne Hospital, Melbourne, Australia \\ ${ }^{6}$ Centre for Biostatistics and Clinical Trials, Peter MacCallum Cancer Centre, Melbourne, Australia \\ ${ }^{7}$ Tissue Bank, Peter MacCallum Cancer Centre, Melbourne, Australia
}

Corresponding author: Gillian Mitchell, gillian.mitchell@petermac.org

Received: 7 Aug 2005 Revisions requested: 25 Aug 2005 Revisions received: 3 Oct 2005 Accepted: 11 Oct 2005 Published: 14 Nov 2005

Breast Cancer Research 2005, 7:R1122-R1131 (DOI 10.1186/bcr1348)

This article is online at: http://breast-cancer-research.com/content/7/6/R1122

(c) 2005 Mitchell et al.; licensee BioMed Central Ltd.

This is an open access article distributed under the terms of the Creative Commons Attribution License (http://creativecommons.org/licenses/by/2.0), which permits unrestricted use, distribution, and reproduction in any medium, provided the original work is properly cited.

\begin{abstract}
Introduction The aim of this study was to collect serial samples of nipple aspirate (NA) and ductal lavage (DL) fluid from women with germline $B R C A 1 / 2$ mutations in order to create a biorepository for use in identifying biomarkers of breast cancer risk.

Methods Between March 2003 and February 2005, 52 women with germline BRCA1 or BRCA2 mutations (median age 43 years, range 27 to 65 years) were scheduled for six-monthly NA, $\mathrm{DL}$ and venesection. DL was attempted for all NA fluid-yielding (FY) and any non-FY ducts that could be located at each visit.

Results Twenty-seven (52\%) women were postmenopausal, predominantly (19/27) from risk reducing bilateral salpingooophorectomy (BSO). FY ducts were identified in $60 \%$ of all women, $76 \%$ of premenopausal women versus $44 \%$ of postmenopausal $(P=0.026)$. Eighty-five percent of women had successful DL. Success was most likely in women with FY ducts (FY 94\% versus non-FY $71 \%(P=0.049)$. DL samples were more likely to be cellular if collected from FY ducts (FY 68\%

versus non-FY 43\%; $P=0.037)$. Total cell counts were associated with FY status (FY median cell count 30,996, range 0 to $>1,000,000$ versus non-FY median cell count 0 , range 0 to $173,577 ; P=0.002)$. Four women (8\%) had ducts with severe atypia with or without additional ducts with mild epithelial atypia; seven others had ducts with mild atypia alone $(11 / 52(21 \%)$ in total). Median total cell count was greater from ducts with atypia $(105,870$, range 1920 to $>1,000,000)$ than those with no atypia (174, 0 to $>1,000,000 ; P \leq 0.001)$.

Conclusion It is feasible to collect serial NA and DL samples from women at high genetic risk of breast cancer, and we are creating a unique, prospective collection of ductal samples that have the potential to be used for discovery of biomarkers of breast cancer risk and evaluate the ongoing effects of risk reducing BSO. DL cellular atypia was not predictive of a current breast cancer and longer follow up is needed to determine whether atypia is an additional marker of future breast cancer risk in this population already at high genetic risk of breast cancer.
\end{abstract}

\section{Introduction}

Germline BRCA1 or BRCA2 mutations are associated with a markedly increased lifetime risk of developing breast cancer $[1,2]$ in female carriers. Not all mutation carriers develop breast cancer, and the age of onset of breast cancer remains unpredictable. Decisions regarding breast cancer risk man- agement can therefore be problematic. Better strategies for risk assessment, early detection and prevention of breast cancer are clearly a priority for research; in particular, there is a pressing need for surrogate biomarkers that are highly specific and sensitive indicators of breast cancer risk.

There is a well established association between atypical ductal epithelium identified by histological biopsy [3], nipple 
aspiration (NA) [4] or fine needle aspiration (FNA) [5] and an increased risk of future breast cancer. The relative risk of developing invasive breast carcinoma for women found to have atypical ductal hyperplasia on breast biopsy is 4.3 times that of the general population and, when combined with a positive family history, the relative risk of invasive breast cancer rises to 9.7 times that of the general population [3]. Women with cellular atypia detected by cytological examination of specimens obtained by NA or FNA have an approximately fivefold higher relative risk of developing breast cancer than women without cellular atypia $[4,6,5]$, which may increase a further six-fold when associated with a family history of breast cancer [4]. Whether the finding of ductal epithelial atypia provides additional prognostic information for women already identified as being at high risk of developing breast cancer by virtue of their $B R C A 1 / 2$ genetic status is not known. Although published reports of NA and FNA have included women at high risk of breast cancer, the proportion of these women who carry a $B R C A 1 / 2$ mutation is unknown and no conclusions can be drawn regarding the utility of these findings specifically in $B R C A 1 / 2$ mutation carriers.

Ductal lavage (DL) can also be used to access the ductal epithelium [7] and promises an improved cell yield over NAF without the more invasive properties of FNA, thus providing better opportunities to identify biomarkers of malignancy. DL also lends itself to repeated sampling of specific ducts, which will enable the monitoring of cytological, biological or molecular changes over time, particularly in response to breast cancer risk-reducing strategies such as bilateral salpingo-oophorectomy (BSO) [8] and chemoprevention $[9,10]$. DL is unlikely to ever sample a sufficient volume of breast to be useful as a breast cancer detection method (screening tool) [11] but it remains uncertain whether it can sample an adequate volume of the intramammary ductal system to be an efficient breast cancer risk-assessment tool $[12,13]$. It is important, therefore, that prospective studies investigate whether $\mathrm{DL}$ is a useful method to identify biomarkers of breast cancer risk.

Investigations into the potential role of $\mathrm{DL}$ as a breast cancer risk-assessment tool have commenced. Epithelial atypia identified by DL is assigned the same clinical significance in the Gail model of risk as atypia in histological tissue sections for determining eligibility for the Study of Tamoxifen and Raloxifene (STAR) trial [14]. It has been suggested that DL can be used to identify women at "high-risk" of breast cancer and who may benefit from tamoxifen chemoprevention [10] by the presence of epithelial atypia $[15,16]$; this may also facilitate decision-making with regards to risk-reducing surgery. However, there is little firm experimental evidence in support of the routine use of $\mathrm{DL}$ as a risk assessment tool at the current time and even less is known about its role in women already at very high risk of breast cancer due to a genetic predisposition to the disease. We initiated a prospective cohort study to collect nipple aspirate fluid (NAF), DL fluid and blood samples from women with germline $B R C A 1 / 2$ mutations with the aim of establishing a biorepository of samples to be used to identify biomarkers of breast cancer risk. Our long-term goal is to examine these samples for ductal epithelial atypia, candidate gene methylation frequency and candidate gene expression by RT-PCR and DNA micro-arrays in addition to ascertaining their proteomic profiles. This report describes our initial experience, with the primary objective being to investigate the practicality of establishing this collection and the nature of the $\mathrm{DL}$ samples collected.

\section{Materials and methods}

Between March 2003 and February 2005, eligible women were recruited from three familial cancer centres (Peter MacCallum Cancer Centre, The Royal Melbourne Hospital, Melbourne, and Westmead Hospital, Sydney, Australia), which they had attended for the purpose of genetic testing. Women aged between 25 and 65 years with at least one breast unaffected by cancer and carrying a deleterious germline BRCA1 or BRCA2 mutation were eligible for the study. Eligible women were invited to participate by letter following permission from their breast specialist. Reasons for exclusion included pregnancy, lactation within the last 12 months, previous subareolar or other surgery that could disrupt the ductal systems, breast implant or breast cancer on the side of the proposed lavage. The study was approved by each Hospital Research Ethics Committee and all participating subjects provided written, informed consent.

Women were scheduled to attend at six-monthly intervals for NA and DL from each breast eligible for the study as well as venesection (for the collection of serum and genomic DNA) for a maximum of three years. Follow up for 10 years following completion of the collection of DL samples with regards breast cancer development is planned. For premenopausal women, we would have preferred to collect samples at the same point in each menstrual cycle but as this proved to be impracticable, details of last menstrual period were obtained for each collection visit. All women were advised to continue with the breast cancer surveillance programme prescribed for them by their breast specialist prior to their participation in this study. At a minimum, this included a recommendation to perform monthly breast self-examination, six-monthly clinical breast examination by their specialist and annual mammography.

\section{Nipple aspirate fluid collection}

After a clinical breast examination, NAF was collected from each breast using the technique as previously described [17]. All NAF collected from a single breast was pooled into $0.5 \mathrm{ml}$ phosphate buffered saline and immediately placed on ice. A $0.25 \mathrm{ml}$ aliquot was immediately frozen at $-80^{\circ} \mathrm{C}$ and the remaining $0.25 \mathrm{ml}$ centrifuged to obtain a cell pellet and supernatant, which were then also stored at $-80^{\circ} \mathrm{C}$ for future studies. 


\section{Ductal lavage collection}

DL was performed with the FirstCyte ${ }^{\mathrm{TM}} \mathrm{DL}$ catheter (Cytyc Corporation, Boxborough, MA, USA) essentially as described [7] with minor modifications. The original DL technique required that only NAF producing ducts were cannulated. As our success rate at obtaining NAF was lower than anticipated, however, we elected to attempt $\mathrm{DL}$ in all eligible breasts regardless of NA success. If NAF was produced, attempts were made to cannulate the NAF-producing duct, but if no NAF was produced, DL was performed on ducts identified by gentle probing of the nipple surface with a microdilator (Cytyc Corporation). We found that the procedure was best performed by two operators, one to insert the catheter and massage the breast in the optimal position and the other to operate the inflow and outflow syringes. We defined a successful lavage as one in which a catheter was seated in a duct and permitted free flow of saline into the duct. Cannulated ducts were temporarily marked with a suture placed in the duct orifice and photographed in addition to marking the location of the duct and the radiation pattern of the instilled intraductal anaesthetic on a nipple diagram in order to facilitate repeated cannulation of the same duct on subsequent visits.

All women completed a 'tolerability questionnaire' immediately after the procedure, scoring the intensity of sensation perceived during the lavage procedure on a visual analogue scale of 0 (no discomfort at all) to 10 (the worst pain imaginable) and comparing the intensity of sensation to that experienced during mammography.

\section{Ductal lavage preparation}

Between 10 and $12 \mathrm{ml}$ of $\mathrm{DL}$ fluid was recovered from each duct; initially $2 \mathrm{ml}$ was separated into $30 \mathrm{ml}$ Cytolyt ${ }^{\text {TM }}$ solution (Cytyc Corporation) for transport to the laboratory for cytological processing and the remainder placed on ice. A significant proportion of our initial samples were considered to have inadequate cellular material for cytological diagnosis (ICMD). Consequently, from September 2003, half the recovered DL fluid was used for cytological analysis. The remaining lavage fluid was temporarily placed on ice and processed within $2 \mathrm{~h}$ into cell pellets of approximately 10,000 cells/pellet and supernatants stored separately at $-80^{\circ} \mathrm{C}$. Total cell counts were obtained using a haemocytometer and Trypan Blue at the start of the handling process.

\section{Cytological examination}

DL samples were processed for cytological examination using the ThinPrep ${ }^{\circledR}$ technique [18], stained by the Papanicolaou method and scored for the proportion of epithelial cells, cytological appearance and epithelial cell atypia by one of us (WM) using the scoring system described in the multi-centre $\mathrm{DL}$ study [7]. Briefly, there were five diagnostic categories: inadequate cellular material for diagnosis (ICMD; samples with $<10$ epithelial cells per slide), benign, mild atypia, severe atypia and malignant. All women were informed of the cytological score.
Table 1

\begin{tabular}{|c|c|c|}
\hline Characteristic & $\mathrm{N}$ & $\%$ \\
\hline Total & 52 & \\
\hline Age (years; median, range) & $43(27-65)$ & \\
\hline \multicolumn{3}{|l|}{$B R C A$ mutation } \\
\hline $\mathrm{A} 1$ & 25 & 48 \\
\hline $\mathrm{A} 2$ & 27 & 52 \\
\hline \multicolumn{3}{|l|}{ Menopause status } \\
\hline Premenopausal & 25 & 48 \\
\hline Postmenopausal & 27 & 52 \\
\hline BSO $<50$ years & 19 & 37 \\
\hline \multicolumn{3}{|l|}{ Current use (study entry) } \\
\hline $\mathrm{OCP}$ & 3 & 6 \\
\hline HRT & 3 & 6 \\
\hline Tamoxifen & 4 & 8 \\
\hline Previous diagnosis of breast cancer & 21 & 40 \\
\hline Parous & 44 & 85 \\
\hline Breast fed & 38 & 73 \\
\hline
\end{tabular}

BSO, bilateral salpingo-oophorectomy; HRT, hormone replacement therapy; OCP, oral contraceptive pill.

If severe cytological atypia or malignant cells were identified, the woman was referred back to her specialist for repeat clinical breast examination and mammography if this had not been performed in the preceding six months, and breast ultrasound and biopsy of any suspicious lesion. Breast MRI was not performed routinely. Suspicious lesions were managed at the discretion of the treating specialist; when no lesion was identified, the woman was reviewed at three-monthly rather than sixmonthly intervals with additional screening investigations performed at the specialist's discretion.

\section{Data collection and statistical analysis}

All data were recorded on study specific case record forms and entered into a database created using Microsoft Access software (Microsoft Corp. Redmond, WA, USA). Data consistency checks were made at the time of data entry and subsequently at the time of statistical analysis. All BRCA1/2 mutation carriers registered on the study prior to February 2005 were included in the analysis. Baseline characteristics of these women were summarised in addition to the characteristics of their breasts and cannulated ducts.

Fisher's exact test was used to compare the proportion of NAF-producing breasts, successful cannulations and ICMD ducts, according to both menopausal status and previous history of breast cancer, parity and breast feeding. The nonparametric Mann-Whitney test was used to compare total cell counts (expressed as both cells $/ \mathrm{ml}$ and total cells) according 
Table 2

\begin{tabular}{|c|c|c|c|c|c|c|}
\hline & \multicolumn{3}{|c|}{ Women } & \multicolumn{3}{|c|}{ Eligible breasts } \\
\hline & $\mathrm{N}$ & $\%$ & $P$ & $\mathrm{~N}$ & $\%$ & $P$ \\
\hline Eligible for study & 52 & & & 83 & & \\
\hline Premenopausal & 25 & 48 & & 43 & 52 & \\
\hline Postmenopausal & 27 & 52 & & 40 & 48 & \\
\hline Previous BC & 21 & 40 & & 21 & 25 & \\
\hline No previous $\mathrm{BC}$ & 31 & 60 & & 62 & 75 & \\
\hline Parous & 44 & 85 & & 68 & 82 & \\
\hline Non-parous & 8 & 15 & & 15 & 18 & \\
\hline Breast fed & 38 & 74 & & 60 & 72 & \\
\hline No breast feeding & 14 & 27 & & 23 & 28 & \\
\hline FY & 31 & 60 & & 45 & 54 & \\
\hline Premenopausal & 19 & 76 & & 30 & 70 & \\
\hline Postmenopausal & 12 & 44 & 0.026 & 15 & 38 & 0.004 \\
\hline Previous BC & 11 & 52 & & 11 & 52 & \\
\hline No previous $\mathrm{BC}$ & 20 & 65 & 0.405 & 34 & 55 & 1.000 \\
\hline Parous & 25 & 57 & & 34 & 50 & \\
\hline Non-parous & 6 & 75 & 0.450 & 11 & 73 & 0.152 \\
\hline Breast fed & 21 & 55 & & 28 & 47 & \\
\hline No breast feeding & 10 & 71 & 0.353 & 17 & 74 & 0.030 \\
\hline No. DL visits (median (range)) & $2(1-5)$ & & & & & \\
\hline Successful DL cannulation & 44 & 85 & & 64 & 77 & \\
\hline $\mathrm{FY}$ & 29 & 94 & & 40 & 89 & \\
\hline Non-FY & 15 & 71 & 0.049 & 24 & 63 & 0.008 \\
\hline Premenopausal & 22 & 88 & & 33 & 77 & \\
\hline Postmenopausal & 22 & 81 & 0.705 & 31 & 78 & 1.000 \\
\hline Previous BC & 17 & 81 & & 17 & 81 & \\
\hline No previous $\mathrm{BC}$ & 27 & 87 & 0.700 & 47 & 76 & 0.769 \\
\hline Parous & 36 & 82 & & 53 & 78 & \\
\hline Non-parous & 8 & 100 & 0.330 & 11 & 73 & 0.738 \\
\hline Breast fed & 32 & 84 & & 47 & 78 & \\
\hline No breast feeding & 12 & 86 & 1.000 & 17 & 74 & 0.772 \\
\hline
\end{tabular}

$P$ is for Fisher's exact test. BC, breast cancer; FY, breasts producing nipple aspirate fluid; $\mathrm{DL}$, ductal lavage.

to menopausal status, NAF-producing status, previous history of breast cancer, parity and breast feeding, development of breast cancer during the study and the presence of DL cytologic atypia. No adjustments have been made for multiple comparisons and all $P$ values are two-sided. Statistical analysis was performed using StatXact version 6.0 (Cytel Software Corporation, Cambridge, MA, USA).

\section{Results}

We recruited 52 women with $B R C A 1 / 2$ mutations (Table 1) with a median age of 43 years (range 27 to 65 years). Twentyseven women (52\%) were postmenopausal, many $(n=19)$ as a consequence of a risk-reducing BSO. Median age at menopause was 45 years (range 30 to 54 years). Twenty-one $(40 \%)$ had a prior diagnosis of unilateral breast cancer. All but two had received adjuvant chemotherapy and only four 


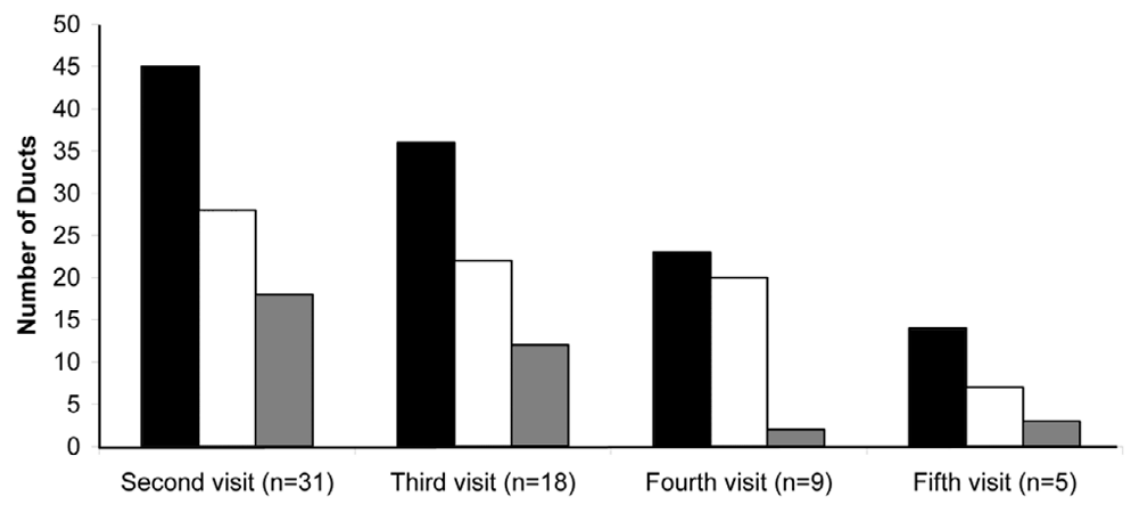

The frequency of individual ducts lavaged on repeat visits per woman. The 'Total number of ducts' equals all ducts ever accessed on at least one previous occasion. 'Repeated ducts' equals ducts re-accessed on that specific visit. 'New ducts' equals a new duct not accessed on a previous visit.

received adjuvant therapy with tamoxifen. None of the 31 unaffected women were taking tamoxifen for breast cancer prevention. Consequently, we were unable to investigate separately the effects of different cancer treatments from the previous diagnosis of breast cancer per se on NA and DL. Eighty-five percent were parous and seventy-three percent had breastfed their children.

NA and DL were attempted in all women on at least one occasion; median two visits, range 1 to 5 visits (Table 2). Success of NA was related to menopause status (70\% of breasts from premenopausal women had fluid-yielding (FY) ducts versus $38 \%$ of breasts from postmenopausal women, $P=0.004)$ but not related to a previous history of contralateral breast cancer (Table 2). Forty-four women (85\%) had a successful DL attempt on at least one occasion. Successful ductal cannulation was related to $\mathrm{FY}$ status $(P=0.008)$ but not related to menopausal status, previous history of contralateral breast cancer or lactation or parity (Table 2). Current exogenous hormone use had no significant effect on FY status (data not shown), but very few patients were current hormone users.

The ability to re-cannulate the same duct on subsequent occasions was determined (Fig. 1). We found that it was more difficult to repeatedly re-cannulate the same duct than we had anticipated, partly due to the close anatomical location of some ducts. For women who attended for more than one lavage appointment, 37\%, 39\%, 13\% and 50\% of previously cannulated ducts could not be re-cannulated at each subsequent visit, respectively. By contrast, a proportion of ducts lavaged at each visit were new ducts never previously cannulated, $40 \%, 33 \%, 9 \%$ and $21 \%$ of ducts cannulated on the second, third, fourth and fifth visits, respectively.

\section{Tolerability}

The DL procedure was well tolerated with a median visual analogue scale reading of $2.8 / 10$ (range 0 to $8 / 10$ ). Three women $(6 \%)$ had not yet commenced mammographic screening. Of the remainder, $33 \%$ of the women thought that the procedure was comparable to the discomfort experienced by mammography, while $33 \%$ reported that the procedure caused more discomfort and $29 \%$ less discomfort than mammography.

\section{Cytological analysis}

DL samples were more likely to have adequate cellular material for diagnosis if they were collected from $\mathrm{FY}$ ducts $(P=0.037$; Table 3). Allocating $50 \%$ of the DL sample for cytological analysis did not reduce the proportion of ICMD samples (data not shown). Similarly, the total cell counts were associated with FY status only $(P=0.002)$. So far, we have found no statistical difference in total counts between the small number $(n=5)$ of women who developed breast cancer during the study versus women who did not.

Examples of cytological scoring categories are illustrated in Fig. 2. Four women $(8 \%)$ had severe atypia diagnosed in at least one DL sample, and three of these had mild atypia noted in at least one of their other DL samples. Seven additional women $(13 \%)$ also had mild atypia alone in at least one DL sample. Overall, there were 20 ducts with atypia from 11 women; 4 of these were classed as severe atypia and 16 as mild atypia. None of the ducts (0/4) with severe atypia were non-FY and two of the ducts with mild atypia were non-FY (2/ 16). Two of eleven (18\%) women with atypia had a previous diagnosis of breast cancer. DL samples with any atypia were significantly more cellular than samples without atypia $(P<$ 0.001 ; Table 3 ). All of the women with severe atypia had a full clinical assessment by a breast surgeon, including an additional mammogram and breast ultrasound. Three of them also had a breast MRI. No suspicious lesions were identified, but 
Table 3

Summary of associations between patient characteristics and ductal lavage cellularity

\begin{tabular}{|c|c|c|c|c|c|c|c|c|}
\hline & \multicolumn{2}{|c|}{ ICMD ducts } & \multicolumn{3}{|c|}{ Cell count/ml } & \multicolumn{3}{|c|}{ Total cell count/specimen } \\
\hline & $\%$ & $P^{1}$ & Median & Range & $P^{2}$ & Median & Range & $P^{2}$ \\
\hline Overall & 39 & & 600 & 0 to 909,090 & & 9481 & 0 to $21,818,160$ & \\
\hline \multicolumn{9}{|l|}{ FY Status } \\
\hline FY duct & 32 & & 1625 & 0 to 909,090 & & 30,996 & 0 to $21,818,160$ & \\
\hline Non-FY duct & 57 & 0.037 & 0 & 0 to 4959 & $<0.001$ & 0 & 0 to 173,577 & 0.002 \\
\hline \multicolumn{9}{|l|}{ Menopausal status } \\
\hline Premenopausal & 28 & & 1000 & 0 to 50,000 & & 22,000 & 0 to 600,000 & \\
\hline Postmenopausal & 51 & 0.034 & 0 & 0 to 909,090 & 0.044 & 0 & 0 to $21,818,160$ & 0.055 \\
\hline \multicolumn{9}{|l|}{ Previous diagnosis of $\mathrm{BC}$} \\
\hline Previous BC & 31 & & 1000 & 0 to 909,090 & & 22,000 & 0 to $21,818,160$ & \\
\hline No BC & 43 & 0.361 & 390 & 0 to 50,000 & 0.191 & 6000 & 0 to $1,229,667$ & 0.189 \\
\hline \multicolumn{9}{|l|}{ Parity } \\
\hline Parous & 35 & & 750 & 0 to 909,090 & & 12,000 & 0 to $21,818,160$ & \\
\hline Non-parous & 58 & 0.073 & 0 & $0-50,000$ & 0.395 & 0 & 0 to 600,000 & 0.261 \\
\hline \multicolumn{9}{|l|}{ Breast feeding } \\
\hline Breast fed & 31 & & 1000 & 0 to 909,090 & & 15,426 & 0 to $21,818,160$ & \\
\hline No breast feeding & 57 & 0.024 & 0 & 0 to 50,000 & 0.091 & 0 & 0 to 600,000 & 0.057 \\
\hline \multicolumn{9}{|l|}{ BC during study } \\
\hline $\mathrm{BC}$ & 20 & & 6666 & 0 to 25,850 & & 79,992 & 0 to 542,850 & \\
\hline No BC & 40 & 0.645 & 500 & 0 to 909,090 & 0.133 & 7688 & 0 to $21,818,160$ & 0.261 \\
\hline \multicolumn{9}{|l|}{ Cytologic atypia } \\
\hline Mild atypia & & & 5355 & 84 to 50,000 & & 105,870 & 1920 to $1,229,667$ & \\
\hline Severe atypia & & & 3591 & 1917 to 18,666 & 0.75 & 113,752 & 48,000 to 447,996 & 0.892 \\
\hline Atypia (mild + severe) & 0 & & 4875 & 84 to 50,000 & & 105,870 & 1920 to $1,229,667$ & \\
\hline No atypia & 50 & $<0.001$ & 14 & 0 to 909,090 & $<0.001$ & 174 & 0 to $21,818,160$ & $<0.001$ \\
\hline
\end{tabular}

Cellularity is expressed both as cells $/ \mathrm{ml}$, to account for variations in the volume of $\mathrm{DL}$ collected, as well as total number of cells/specimen in order to permit comparisons between our results and other published studies. $P^{1}=$ Fisher's exact test; $P^{2}=$ Mann-Whitney test. BC, breast cancer; ICMD, inadequate cellular material for diagnosis; FY, ducts producing nipple aspirate fluid.

one of them had two fibroadenomas diagnosed by imaging and confirmed by biopsy in the breast with atypia.

Five women, all with BRCA1 mutations, were diagnosed with breast cancer (median five months following study entry); the features of their cancers and associated DL samples are summarised in Table 4. Only one cancer was detected through a scheduled annual screening mammogram, and was clinically impalpable at the time of diagnosis. All four other cancers were interval cancers discovered by self-detection of a new breast lump. All prior screening mammograms and clinical breast examinations were reported as normal. One woman had mild cytological atypia in the DL sample from the cancercontaining breast but no cytological atypia was identified in the DLs from the cancer-containing breast of the other three women successfully lavaged. Thus, there appeared to be no correlation between the presence of cytological atypia and the short term development of cancer.

\section{Discussion}

This is the first published study, to our knowledge, to describe the findings from serial NA and DL in a cohort of women with germline mutations in BRCA1 and BRCA2 genes. We have demonstrated that it is both acceptable and feasible to collect these samples and we have established a prospective collection of samples with ongoing epidemiological data that will be available for future breast cancer biomarker discovery. 
Figure 2

(a)

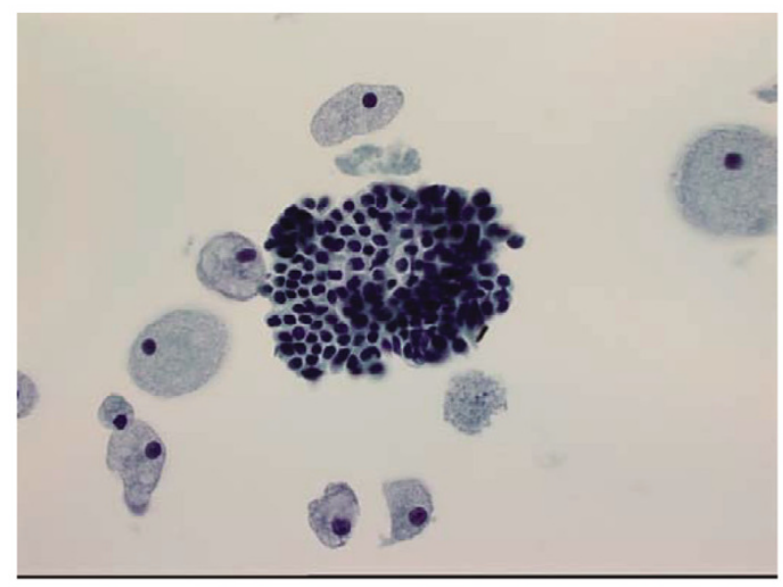

(b)

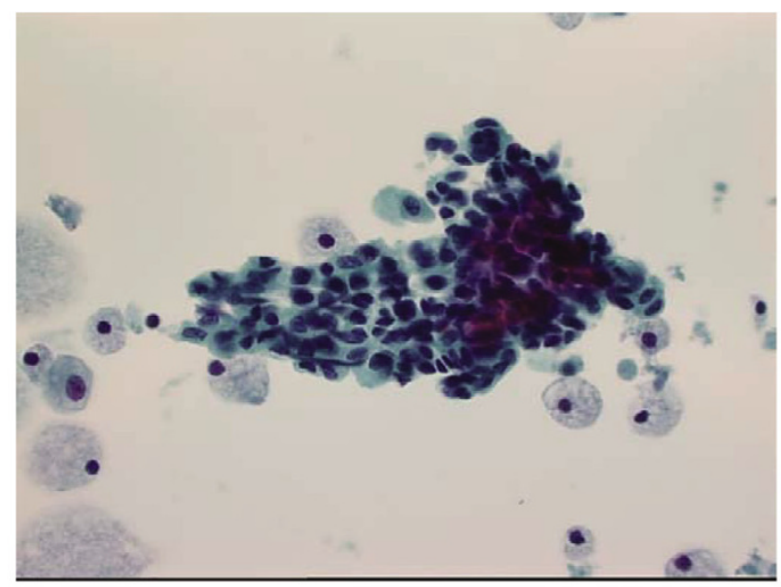

(c)

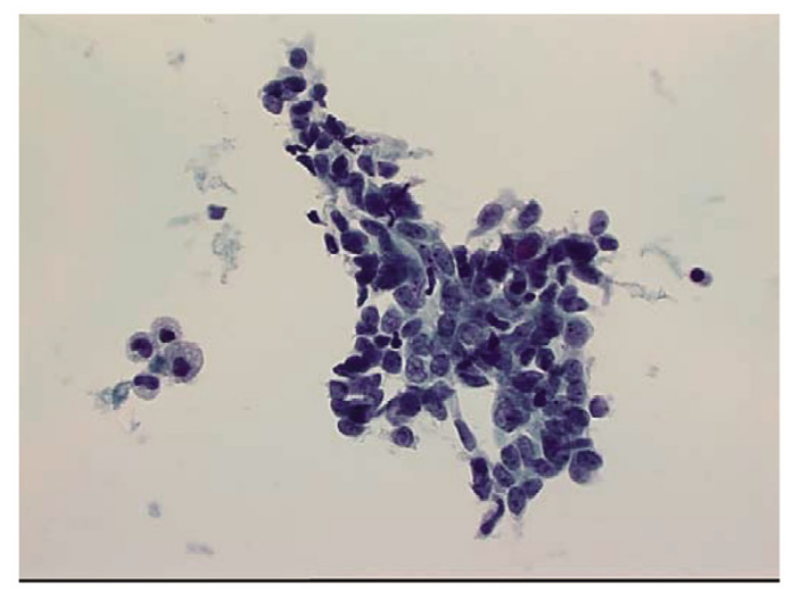

Examples of ductal epithelial cells collected by ductal lavage. (a) Benign ductal epithelial cells. (b) Epithelial cells with mild atypia. (c) Epithelial cells with severe atypia.
We found that we could obtain ductal fluid by NA in $60 \%$ of our cohort overall, but that NAF was more often obtained from premenopausal women. Our overall figures are less successful than reported by most (48\% to 99\%) [19-21,7,22,23]. One explanation is that we had a high proportion of postmenopausal women in our cohort (52\%) and the proportion of premenopausal women with FY ducts in our cohort is significantly higher than the proportion of postmenopausal women with them. Additional explanations could include the persistence with which the collection of NAF was pursued. For studies of NAF only, it is appropriate to be particularly persistent but in our study, as this was the preliminary to subsequent lavage attempts, we had concerns regarding engorgement of the nipple as a consequence of vigorous attempts to elicit NAF and time constraints were also important. It is possible that if we had been more persistent our overall NAF success rates may have improved a little, although we consider it unlikely that this would have changed our results substantially.

Half of the women in our cohort were postmenopausal despite the median age of only 43 years, predominantly because of risk-reducing BSO (19/27 postmenopausal women). Seventysix percent of the premenopausal women had FY ducts in contrast to forty-four percent of postmenopausal women. Similar low rates of $F Y$ ducts in ovariectomised women have been observed previously; BL King, Yale, found FY ducts in only $23 \%$ of women with oophorectomy with or without selective estrogen receptor modulator (SERM) use (personal communication). Conversely, Kurian et al. [23] found no effect of menopausal status on the ability to elicit NAF; however, they had a lower overall NAF success rate (48\% compared to $60 \%$ in our study), which may account for this apparent discrepancy in results. During the course of our study, more women are planning to have a risk-reducing BSO and we will be able to investigate the temporal relationship between NAF production/DL cellularity and BSO.

The ability to re-cannulate the same duct on repeated occasions was less successful than we had anticipated (Fig. 1). Frequently, it was simply that we were unable to locate the duct orifice or, to a lesser extent, the duct was perforated during the cannulation attempt. On most occasions, we could be sure that the same and/or different ducts were cannulated as a consequence of the combined information from the photographs, nipple diagrams and anaesthetic radiation pattern. Despite this information, however, it is possible that we may have re-cannulated the same duct but scored it at a different, although close, location or conversely, that we have recorded a successful re-cannulation but in fact cannulated a different duct due to the close proximity of two duct orifices.

If the DL sample had adequate material for cytological diagnosis (non-ICMD samples), the cellularity was comparable to previous reports [7]. In contrast to previous reports, however, we found that a higher proportion of our samples were catego- 
Table 4

Demographic, tumour and ductal lavage characteristics of women who developed breast cancer after study entry

\begin{tabular}{|c|c|c|c|c|c|}
\hline & \multicolumn{5}{|c|}{ Subject } \\
\hline & PMC13 & PMC11 & PMC14 & PMC15 & $\mathrm{RMH08}$ \\
\hline Age (years) & 53 & 51 & 41 & 48 & 37 \\
\hline$B R C A$ mutation & $\mathrm{A} 1$ & $\mathrm{~A} 1$ & $\mathrm{~A} 1$ & $\mathrm{~A} 1$ & $\mathrm{~A} 1$ \\
\hline Menopause status & Post & Post & Pre & Post & Pre \\
\hline Prior contralateral breast cancer (age in years) & No & Yes (42) & Yes (35) & Yes (38) & Yes (34) \\
\hline Previous mammogram (months) & 12 (normal) & 7 (normal) & 5 (normal) & 5 (normal) & 7 (normal) \\
\hline Previous CBE (months) & 6 & 1 & 5 & 5 & 7 \\
\hline 'Regular' BSE'a & Yes & Yes & Yes & Yes & Yes \\
\hline Mode of detection & Mammography & Self & Self & Self & Self \\
\hline Distance from nipple $(\mathrm{cm})$ & 5 & 3 & Not recorded & Not recorded & 2 \\
\hline Histological characteristics & Atypical medullary & Lobular & Ductal & Ductal & Ductal \\
\hline Size $(\mathrm{mm})$ & 5.2 & 20 & $\begin{array}{c}10,14,10 \\
(\mathrm{X} 3 \text { separate foci) }\end{array}$ & 1.8 & 5 \\
\hline Grade & 3 & 3 & 3 & 3 & 3 \\
\hline ER status & Negative & Negative & Negative & Negative & Negative \\
\hline PR status & Negative & Negative & Negative & Negative & Negative \\
\hline Nodes & Negative & Negative & Negative & Negative & Negative \\
\hline \multicolumn{6}{|l|}{ Ductal lavage } \\
\hline Previous (months) & 5 & 1 & 5 & 12 & 4 \\
\hline No. ducts cannulated/breast & 1 (X1occ) & 2 (X1occ) & 1 (X2occ) & 1 (X1occ) & Unsuccessful \\
\hline Cell count (duct)/ml & 6,666 & $2,500,6,666$ & $47,700+4,000$ & 15,000 & \\
\hline Total cell count (duct) & 79,992 & $35,000,93,324$ & $525,555+40,000$ & 180,000 & \\
\hline Cytology score & Mild atypia & Benign & Benign & No epithelial cells & \\
\hline
\end{tabular}

a'Regular' as reported by subject (frequency not recorded). BSE, breast self examination; CBE, clinical breast examination; ER, oestrogen receptor; PR, progesterone receptor.

rised as ICMD (39\% in contrast to $22 \%$ [7]). The higher proportion of ducts with ICMD may be due to a variety of factors. We consider menopausal status to be the most important factor associated with cellularity, but the practice of allocating only a small proportion (initially $20 \%$ then later $50 \%$ ) of the sample, in contrast to previous reports in which the entire lavage sample was used for cytological analysis, may also have contributed to the higher ICMD rate. We found that DL cellularity was related to both $\mathrm{FY}$ and menopausal status, which is consistent with the close relationship between these two factors. We are not able to comment on the effect of prior exposure to chemotherapy or tamoxifen or current exogenous hormone use as separate categories on cannulation success rates or sample cellularity as almost all women previously affected by breast cancer had received chemotherapy and few received tamoxifen.
Four women (8\%) were identified with severe cytological atypia (in at least one duct on at least one occasion) and 7/52 $(13 \%)$ with mild cytological atypia, which is consistent with the results from the multicentre DL study (6\% and $17 \%$ of women had severe or mild atypia, respectively [7]) and from DL studies of other high-risk women in which 23\% (7/30) [24] and $28 \%(17 / 75)$ [23] had any atypia (severe or mild). We might have expected to see a higher rate of atypia in our study if the hypothesis that atypia is related to future breast cancer risk is correct, as the women in our study should be at very high risk due to their genetic status. However, the large numbers of women who have undergone risk-reducing BSO in our study may have reduced the overall breast cancer risk in our cohort. The majority of samples with atypia in our study (90\%) were from FY ducts, in contrast to $29 \%$ reported by Kurian et al. [23]. It is difficult to postulate a biological explanation for 
this discrepancy but it is possible that it is due to a combination of the small numbers of samples with atypia in each study, in addition to the known difficulties in cytological interpretation. All the atypical samples in the Kurian et al. study were scored as mildly, rather than severely, atypical, as were most of ours, and it is the differentiation between benign and mildly atypical that is the most debated in cytological scoring.

Five women were diagnosed with breast cancer during our study; one had only mild cytological atypia while the others had no atypia in their DL samples. These women are likely to have had an established malignancy at study entry, although this was not detected by pre-study assessment. Our results are consistent with previous reports that have suggested that both NAF and DL fluid have low sensitivity for the identification of an established malignancy. For NAF, only a low percentage of specimens contain severely atypical or malignant cells, even when the aspirate is obtained from a known cancer-bearing breast (sensitivity $4 \%$ [22] to $21 \%$ [22,19]). Two studies have reported on the low sensitivity (41\% [25], 11\% (Wiley, K.: Histology of intraductal lesions - correlation and sampling issues. Lynn Sage Breast Cancer Symposium, Chicago 2003,) [26]) of $\mathrm{DL}$ for established breast cancer. The reasons for such low sensitivity are uncertain, but are possibly related to sampling error by the cannulation of only a limited number of ducts per breast and the blockage/disruption of the ductal system by non-invasive or invasive tumours.

We believe that it is important to be aware of the poor correlation between $\mathrm{DL}$ atypia and current breast cancer and that the significance of detecting $\mathrm{DL}$ atypia in a high-risk woman is unknown. The finding of no atypia should not reassure a highrisk woman that no malignancy is present and she should be encouraged to continue with regular breast self examination, clinical breast examination and mammography. The finding of atypia requires investigation to exclude malignancy, but we do not consider that there is sufficient evidence currently to consider DL atypia as an additional risk factor in support of prophylactic mastectomy in an otherwise high-risk population.

\section{Conclusion}

Our results demonstrate that $\mathrm{DL}$ is an acceptable, minimally invasive method of repeatedly accessing the breast ductal environment, although it requires further validation before it can be established as a breast cancer risk assessment tool, particularly in the high-risk population. It does not appear to be a sensitive breast cancer screening method. We are creating a prospective repository of biologic samples that have the potential to be used to identify biomarkers of breast cancer risk in a high-risk population. Two further cohorts of 50 $B R C A 1 / 2$ mutation carriers each in the UK and US are being recruited using a similar protocol, which will permit a combined analysis of results in the future. In the first two years of our study, five women have developed breast cancer, consistent with published rates of breast cancers in this high-risk group $[1,2,27]$. If similar rates of breast cancer development are observed in the UK and US centres, it is probable that these samples can be used to identify cytological, biological and molecular biomarkers for breast cancer risk in women with germline $B R C A 1 / 2$ mutations.

\section{Competing interests}

The authors declare that they have no competing interests.

\section{Acknowledgements}

To all the women who have kindly taken part in this study. Cytyc Corporation who generously provided Thin Prep materials. Melbourne Pathology who provided Thin Prep processing. All the breast surgeons providing clinical support, in particular Caroline Baker, Belinda Brown, Michael Henderson, Bruce Mann and David Speakman. Research support was provided by the National Health and Medical Research Council, Australia (YCA), the National Breast Cancer Foundation Goodman Fielder Scholarship, Australia (ES) and the Victorian Breast Cancer Research Consortium Inc., Australia. This work was presented, in part, as a poster presentation at the 2004 San Antonio Breast Cancer Conference.

\section{References}

1. Ford D, Easton DF, Stratton M, Narod S, Goldgar D, Devilee P, et al:: Genetic heterogeneity and penetrance analysis of the BRCA1 and BRCA2 genes in breast cancer families. The Breast Cancer Linkage Consortium. Am J Hum Genet 1998, 62:676-689.

2. Antoniou A, Pharoah PD, Narod S, Risch HA, Eyfjord JE, Hopper $\mathrm{JL}$, et al:: Average Risks of Breast and Ovarian Cancer Associated with BRCA1 or BRCA2 Mutations Detected in Case Series Unselected for Family History: A Combined Analysis of 22 Studies. Am J Hum Genet 2003, 72:1117-1130.

3. Page DL, Dupont WD, Rogers LW, Rados MS: Atypical hyperplastic lesions of the female breast. A long-term follow- up study. Cancer 1985, 55:2698-2708.

4. Wrensch MR, Petrakis NL, King EB, Miike R, Mason L, Chew KL, et al.: Breast cancer incidence in women with abnormal cytology in nipple aspirates of breast fluid. Am J Epidemiol 1992, 135:130-141.

5. Fabian CJ, Kimler BF, Zalles CM, Klemp JR, Kamel S, Zeiger S, et al.: Short-term breast cancer prediction by random periareolar fine-needle aspiration cytology and the Gail risk model. J Nat/ Cancer Inst 2000, 92:1217-1227.

6. Wrensch MR, Petrakis NL, Miike R, King EB, Chew K, Neuhaus J, et al.: Breast cancer risk in women with abnormal cytology in nipple aspirates of breast fluid. J Natl Cancer Inst 2001, 93:1791-1798.

7. Dooley WC, Ljung BM, Veronesi U, Cazzaniga M, Elledge RM, O'Shaughnessy JA, et al.: Ductal lavage for detection of cellular atypia in women at high risk for breast cancer. J Natl Cancer Inst 2001, 93:1624-1632.

8. Rebbeck TR, Lynch HT, Neuhausen SL, Narod SA, Van't Veer L, Garber JE, et al.: Prophylactic oophorectomy in carriers of BRCA1 or BRCA2 mutations. N Engl J Med 2002, 346:1616-1622.

9. Fisher B, Costantino JP, Wickerham DL, Redmond CK, Kavanah $\mathrm{M}$, Cronin WM, et al: Tamoxifen for prevention of breast cancer: report of the National Surgical Adjuvant Breast and Bowel Project P-1 Study. J Natl Cancer Inst 1998, 90:1371-1388.

10. Chlebowski RT, Col N, Winer EP, Collyar DE, Cummings SR, Vogel VG III, et al.: American Society of Clinical Oncology technology assessment of pharmacologic interventions for breast cancer risk reduction including tamoxifen, raloxifene, and aromatase inhibition. J Clin Oncol 2002, 20:3328-3343.

11. Khan SA, Wiley EL, Rodriguez N, Baird C, Ramakrishnan R, Nayar $\mathrm{R}$, et al:: Ductal lavage findings in women with known breast cancer undergoing mastectomy. J Natl Cancer Inst 2004, 96:1510-1517. 
12. Badve S: Ductal lavage and its histopathologic basis: a cautionary tale. Diagn Cytopathol 2004, 30:166-171.

13. Vogel VG: Atypia in the assessment of breast cancer risk: implications for management. Diagn Cytopathol 2004, 30:151-157.

14. Vogel VG, Costantino JP, Wickerham DL, Cronin WM: Re: tamoxifen for prevention of breast cancer: report of the National Surgical Adjuvant Breast and Bowel Project P-1 Study. J Nat/ Cancer Inst 2002, 94:1504.

15. O'Shaughnessy JA, Ljung BM, Dooley WC, Chang J, Kuerer HM, Hung DT, et al:: Ductal lavage and the clinical management of women at high risk for breast carcinoma: a commentary. Cancer 2002, 94:292-298.

16. Morrow M, Vogel V, Ljung BM, O'Shaughnessy JA: Evaluation and management of the woman with an abnormal ductal lavage. J Am Coll Surg 2002, 194:648-656.

17. Mitchell G, Trott PA, Morris L, Coleman N, Sauter E, Eeles RA: Cellular characteristics of nipple aspiration fluid during the menstrual cycle in healthy premenopausal women. Cytopathology 2001, 12:184-196.

18. Zahniser DJ, Hurley AA: Automated slide preparation system for the clinical laboratory. Cytometry 1996, 26:60-64.

19. King EB, Chew KL, Petrakis NL, Ernster VL: Nipple aspirate cytology for the study of breast cancer precursors. J Natl Cancer Inst 1983, 71:1115-1121.

20. Buehring GC: Screening for breast atypias using exfoliative cytology. Cancer 1979, 43:1788-1799.

21. Sauter ER, Ross E, Daly M, Klein-Szanto A, Engstrom PF, Sorling $A$, et al:: Nipple aspirate fluid: a promising non-invasive method to identify cellular markers of breast cancer risk. $\mathrm{Br} J$ Cancer 1997, 76:494-501.

22. Krishnamurthy S, Sneige N, Thompson PA, Marcy SM, Singletary $\mathrm{SE}$, Cristofanilli $\mathrm{M}$, et al:: Nipple aspirate fluid cytology in breast carcinoma. Cancer 2003, 99:97-104.

23. Kurian AW, Mills MA, Jaffee M, Sigal BM, Chun NM, Kingham KE, et al:: Ductal lavage of fluid-yielding and non-fluid-yielding ducts in BRCA1 and BRCA2 mutation carriers and other women at high inherited breast cancer risk. Cancer Epidemiol Biomarkers Prev 2005, 14:1082-1089.

24. Hartman AR, Daniel BL, Kurian AW, Mills MA, Nowels KW, Dirbas $\mathrm{FM}$, et al.: Breast magnetic resonance image screening and ductal lavage in women at high genetic risk for breast carcinoma. Cancer 2004, 100:479-489.

25. Brogi E, Robson M, Panageas KS, Casadio C, Ljung BM, Montgomery $L$ : Ductal lavage in patients undergoing mastectomy for mammary carcinoma: a correlative study. Cancer 2003, 98:2170-2176.

26. Wiley K: Histology of intraductal lesions - correlation and sampling issues. Lynn Sage Breast Cancer Symposium, Chicago 2003.

27. Metcalfe K, Lynch HT, Ghadirian P, Tung N, Olivotto I, Warner E, et al.: Contralateral breast cancer in BRCA1 and BRCA2 mutation carriers. J Clin Oncol 2004, 22:2328-2335. 